\title{
A clinician's view of mixed health care in Quebec
}

\author{
Interview with Dr. Lawrence A. Stein, Radiologist \\ Interviewed by Samuel Lapalme-Remis for the MJM
}

MJM: Please describe how your divide you practice on a week-to-week basis.

Dr. Stein: I actually spend about $90 \%$ of my time in the hospital system. I've done it that way since 1974. Our group has always had a community clinic. I don't like to use the word "private" clinic, it's a bit of a misnomer because until about quite recently, patients didn't have to pay for the imaging that was available at these clinics - chest x-rays, lumbar/spine, mammography, barium studies. These clinics started in the late 1960's as an outlet for patients to get their outpatient imaging done using their medicare card without relying on an expensive hospital infrastructure. Our group had such a clinic, as did radiologists at most other hospitals.

Then about five or six years ago, these clinics started to include CT, MRI, PET scanning and even nuclear medicine. This was new in that these procedures weren't covered by the medicare card and therefore patients had to pay for that. The Quebec law is very clear regarding radiological procedures; if it's not insured within a hospital, you can charge for it outside a hospital. For some other specialities, there's more of a grey zone.

MJM: What changed five or six years ago?

Dr. Stein: What changed is that CT, MRI and ultrasound just became more used and everyone saw that there was probably a group of patients that would be able to afford or have insurance for these procedures, and who would benefit from them.

At our clinic downtown, we offer everything we offered since 1967, and since 2000 we've added to that these advanced imaging procedures, so $60 \%$ of our volume is medicare covered and $40 \%$ isn't. It's legal to do this in Quebec, as it is in BC and Alberta. Also, in

*To whom correspondence should be addressed:

Lawrence Stein

Royal Victoria Hospital

Radiologist-in-Chief

687 Pine Avenue West

Montreal, Quebec

H3A 1A1

lawrence.stein@muhc.mcgill.ca
Quebec, most private health-insurance programs that people are enrolled in as an employment benefit cover these kind of procedures, sometimes up to $100 \%$, and usually about $80 \%$. This is unique to Quebec; if you have a job, you probably have this kind of insurance.

MJM: What was the reaction when you introduced these new services not covered by medicare?

Dr. Stein: Well, in 2000 we moved from a smaller office where we had only offered the covered services and opened a new and larger office where we offered the advanced imaging as well. At the time we developed and opened it, it was fairly unique. Had we done it five years earlier, I think we would have had gotten a very negative response, but at the time we actually did it we got a fairly positive media response. The media were very receptive.

MJM: What were some of the concerns that you heard from the media?

Dr. Stein: The nature of the debate was what people fear most when they hear about private health care, and that's what happening south of us. They do not want the American system in Canada. Quite frankly, I don't think there are many Canadian doctors who want the American system in Canada either, but that's what patients fear. They see spiralling costs and a huge volume of patients who can't afford health care in the United States, and that's what they're bombarded with in the media. Canadians are frightened about that. That's the negative part. What Canadians don't always know is how good the systems in Europe are, like in France, Germany and the UK. These systems offer both government-sponsored and alternative health care working together. Canada is more like Europe overall than like the US. Of course, pressure does need to be maintained on the government to make sure that the public system is properly supported. I've had careerlong commitment to and support for a strong, vibrant, well-funded and properly staffed public health care system where there is timely access to quality imaging for all Canadians.

MJM: Per unit time, is it more profitable for a 
radiologist to do a procedure inside or outside a hospital?

Dr. Stein: It's just about the same. It's not to my advantage or disadvantage to work at the clinic over the hospital.

MJM: How would you describe the work you do at the clinic?

Dr. Stein: As I mentioned before, I spend about 90\% of my time in the hospital; the clinic is a nice break for me. The hospital is a very high-pressure, difficult, not very efficient environment to work in. Going to the clinic gives me a little bit of a respite.

We're doing very good imaging at the clinic. It's the same community of patients and they're not using hospital resources. Some people accused us at the beginning of catering to the "worried well." In fact, we see more pathology per capita at the clinic than we do at the hospital.

MJM: When a patient pays out of their own pocket, as opposed to when they put down a card and don't have to pay directly, do you sense any difference in the interaction that you have with them?

Dr. Stein: No. Whether a patient is in the hospital or in the clinic, they'll see no difference from me. I don't think they perceive any difference.

MJM: But the patients themselves, they don't demand more?

Dr. Stein: They may be a little more demanding. They will not tolerate waiting. If the appointment is at nine o'clock, they expect to be seen at nine. In the hospital you can often have a patient who has been waiting for a considerable amount of time. That won't be tolerated at the clinic.

It's interesting because that carries over to the patients in the clinic who use their medicare card. They expect to be taken care of on time too. It's just the environment.

MJM: How else does the population at the clinic differ from that of the hospital?

Dr. Stein: Obviously, in the hospital we see sicker patients, patients who are less ambulatory. Also, there's two groups at the clinic, those who use their medicare card and those who are paying or have insurance. Those who are paying are probably a higher socio-economic group.

MJM: Is that a concern of yours?

Dr. Stein: Yes and no. I look on that in two ways. The first thing is, whose fault is it? If a patient needs a CT scan and can't get it in an appropriate length of time, it's the government's fault. So the fact that we're offering it to some patients who can afford it or can get the insurance, does it bother me? Yes, it bothers me; I'm concerned about it. But it's the fault of the government for not providing the resources that are necessary to deal with the ageing population and higher technology. In imaging, medicare is no longer sustainable. It may have been good for 1967 to 1997, but it can't keep up with the high cost in imaging. Something has to give, the money has to come from somewhere.

MJM: Where would you hope that the money will come from in the future?

Dr. Stein: I think that for the future, we have to allow both parts, the state-supported and the alternative have to be supported and allowed to thrive. And there may even be situations where there's a link between the two. The government may see that it's more worthwhile to have things done in the clinic than in the hospital. But right now they'd rather have the patient wait.

What I'm for is timely access to quality imaging. Full stop. I fight every day of my life to get more resources in the hospital. We don't have enough receptionists, typists, technologists, radiologists. It's hard. Right now we're capped by the number of radiologists, yet our volume of work in hospital has increased. It's forcing us all to work too hard. In the hospital, I'm often forced to manage three patients at the same time when it should be one patient at one time. It's hard to get a day's work done without constant interruptions.

I don't have that at the clinic. At the clinic, $100 \%$ of the time I'm attentive to what I'm doing and dealing with the patient at hand.

MJM: Do you find this makes a big difference in terms of the quality of care that you're able to provide?

Dr. Stein: You learn how to practice in the hospital. You learn how to do it well. If you can't do it, you will leave the hospital. I've had medical students ask me, "how can you practice like that?"; they can see the interruptions that I deal with. I just say, "you learn how to do it."

There are times where I have thought that each of us is trying to do too much. I have to think that that is prone to making errors.

MJM: What advice would you give a young radiologist beginning their practice in Quebec?

Dr. Stein: I would say that the type of practice you want is a combined hospital and outside-clinic practice. We have a beautiful profession in that we can do both of these things. The hospital allows us to do many things you could never do in a clinic. You might be bored as a young radiologist doing just an outside practice.

Lawrence A. Stein, MD, FRCPC, is Chief of Diagnostic Radiology at the Royal Victoria Hospital and Associate Professor of Radiology at McGill University. He is a past President of the Canadian Association of Radiologists. Dr. Stein is on the Board of Directors of the Westmount Square Imaging Centre, where he works as a practicing radiologist. 